\title{
Optical Spectra Properties and Continuous-Wave Laser Performance of Tm, Y:CaF 2 Single Crystals
}

\author{
Jingxin Ding, ${ }^{1,2}$ Beibei Zhao, ${ }^{1}$ Weiwei Ma, ${ }^{1}$ Hao Yu, ${ }^{1}$ Xiaobo Qian, ${ }^{1}$ Lingchen Kong, \\ Jingya Wang, ${ }^{1}$ Guoqiang Xie $\mathbb{D},{ }^{3}$ Anhua Wu, ${ }^{1}$ Fanming Zeng, ${ }^{2}$ and Liangbi Su $\mathbb{D}^{1,4}$ \\ ${ }^{1}$ Synthetic Single Crystal Research Center, Key Laboratory of Transparent and Opto-Functional Inorganic Materials, \\ Shanghai Institute of Ceramics, Chinese Academy of Sciences, Shanghai, China \\ ${ }^{2}$ School of Materials Science and Engineering, Changchun University of Science and Technology, Changchun 130022, China \\ ${ }^{3}$ Key Laboratory for Laser Plasmas (Ministry of Education), Collaborative Innovation Center of IFSA (CICIFSA), \\ Department of Physics and Astronomy, Shanghai Jiao Tong University, Shanghai 200240, China \\ ${ }^{4}$ State Key Laboratory of High Performance Ceramics and Superfine Microstructure, Shanghai Institute of Ceramics, \\ Chinese Academy of Sciences, Shanghai, China
}

Correspondence should be addressed to Liangbi Su; suliangbi@mail.sic.ac.cn

Received 12 August 2017; Revised 19 November 2017; Accepted 13 December 2017; Published 23 January 2018

Academic Editor: Wonho Jhe

Copyright (C) 2018 Jingxin Ding et al. This is an open access article distributed under the Creative Commons Attribution License, which permits unrestricted use, distribution, and reproduction in any medium, provided the original work is properly cited.

\begin{abstract}
3 at. $\% \mathrm{Tm}, x$ at. $\% \mathrm{Y}: \mathrm{CaF}_{2}$ crystals $(x=0,0.5,1,2$, and 3$)$ were grown by the vertical Bridgman method and investigated. Codoping $\mathrm{Y}^{3+}$ ions can manipulate the local structure of $\mathrm{Tm}^{3+}$ ions in the $\mathrm{CaF}_{2}$ crystal and then improve the spectroscopic properties. Compared with 3 at.\% Tm: $\mathrm{CaF}_{2}, 3$ at.\% Tm, 3 at.\% Y:CaF ${ }_{2}$ crystal has several advantages. Firstly, the absorption cross section is improved from $0.35 \times 10^{-20} \mathrm{~cm}^{-2}$ to $0.45 \times 10^{-20} \mathrm{~cm}^{-2}$ at $767 \mathrm{~nm}$, and the fluorescence intensity had elevated 3.4 times. Secondly, the linewidth of the fluorescence spectrum and lifetime also increased from $164 \mathrm{~nm}$ to $191 \mathrm{~nm}$ and from $6.16 \mathrm{~ms}$ to $8.15 \mathrm{~ms}$ at room temperature, respectively. Furthermore, quantum efficiency improved from $58.2 \%$ to $80.3 \%$. The maximum laser output power of $583 \mathrm{~mW}$ and slope efficiency of $25.3 \%$ were achieved in 3 at. $\% \mathrm{Tm}, 3$ at. $\%$ Y:CaF $\mathrm{C}_{2}$ crystal under $790 \mathrm{~nm}$ diode pumping.
\end{abstract}

\section{Introduction}

Calcium fluorides, as laser substrates, possess various advantages of large size, high thermal conductivity, well controlled crystal growth processes, and low nonlinear refractive coefficient. Trivalent rare-earth ions, like $\mathrm{Tm}, \mathrm{Nd}, \mathrm{Pr}$, doped $\mathrm{CaF}_{2}$ crystals behave broad, smooth absorption and emission spectra due to heterovalent substitution of $\mathrm{Ca}^{2+}$ within the structure without loss of structural integrity [1]. Various $\mathrm{RE}^{3+}$ optical centers could be formed in this fluoride by substituting divalent cation ions, and the excessive charge of rare-earth ions is compensated by interstitial fluorine. The $\mathrm{Nd}^{3+}$ doped $\mathrm{CaF}_{2}$ crystal as a laser-pumped-amplifier medium has been abandoned due to a very serious concentration quenching effect which results from the clustering of the neodymium ions and kinds of cross-relaxation type energy transfer processes, which weaken their emission quantum efficiency [2].
However, the $\left[\mathrm{Nd}^{3+}-\mathrm{Nd}^{3+}\right]$ quenching pairs in clusters can be easily dissociated by codoping buffer ions such as $\mathrm{Y}^{3+}$ ions [3-8], $\mathrm{La}^{3+}$ ions [9], and $\mathrm{Sc}^{3+}$ ions [10]. For example, $\mathrm{Nd}, \mathrm{Y}: \mathrm{CaF}_{2}$ crystal, $\mathrm{Y}^{3+}$ ions were codoped in $\mathrm{Nd}: \mathrm{CaF}_{2}$ crystal which substitute for $\mathrm{Ca}^{2+}$ forming complicated local structure that performs an effect on spectroscopic properties [8].

As the solid-state lasers medium, the doped $\mathrm{Tm}^{3+}$ calcium fluoride crystal proves the potential to achieve efficient compact diode-pumped lasers with an oscillation wavelength near $2 \mu \mathrm{m}$ which could be directly pumped around $790 \mathrm{~nm}$ $\left({ }^{3} \mathrm{H}_{6} \rightarrow{ }^{3} \mathrm{H}_{4}\right.$ absorption transition) due to much lower nonradiative losses caused by multiphonon relaxation [11]. Tm ions act both as a sensitizer and activator in a single-doped sample, meaning that a higher concentration is necessary for effective absorption of $800 \mathrm{~nm}$ laser excitation. Compared to oxide crystals, pure $\mathrm{CaF}_{2}$ crystal has a thermal conductivity as high as $10 \mathrm{~W} / \mathrm{cm} \cdot \mathrm{K}[12]$ and low phonon energy 


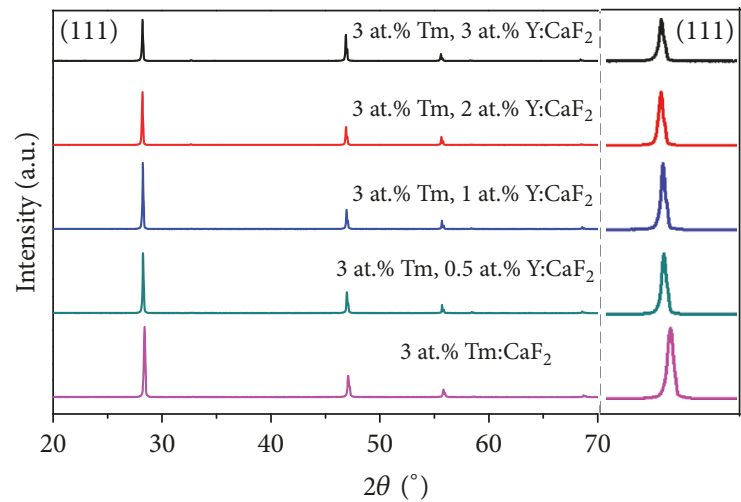

(a)

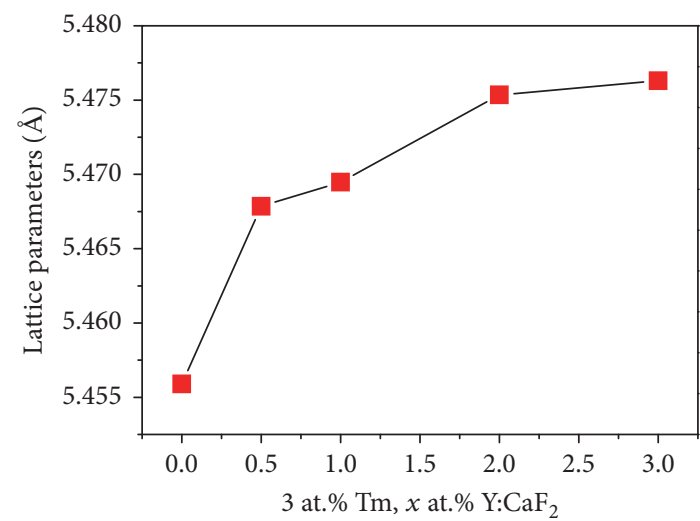

(b)

FIgURE 1: The XRD patterns (a) and lattice parameters (b) of 3 at. $\%$ Tm, $x$ at. $\%$ Y:CaF ${ }_{2}$ crystals.

(maximum value of $495 \mathrm{~cm}^{-1}$ ) [13], making it very suitable for a laser host crystal and becoming one of the first laser hosts in the early $1960 \mathrm{~nm}$. The predecessors have done some researches on $\mathrm{Tm}^{3+}$ doped $\mathrm{CaF}_{2}$ single crystals and found that $\mathrm{Tm}: \mathrm{CaF}_{2}$ crystals possessed broadband absorption and emission properties $[11,14,15]$. The spectroscopic investigation on $\mathrm{Tm}^{3+}$ doped crystals indicates that $\mathrm{Tm}^{3+}$ ions interactions occur (forming the cross relaxation) at relatively low dopant concentrations (nearly 1\%), that is, two excited ions in the ${ }^{3} \mathrm{~F}_{4}$ upper ground level 7F6 for one absorbed pump photon. The distinction between isolated and clustered ions is observed in the emission spectra due to different doped concentration. Besides, nonradiative processes related to ${ }^{3} \mathrm{H}_{5}-{ }^{3} \mathrm{~F}_{4}$ induced by [Tm-Tm] clusters in the crystals could result in strong heat generation and distortions reducing quantum efficiency [16]. To achieve higher power laser at $2 \mu \mathrm{m}$, one of the efficient ways is to prepare $\mathrm{Tm}: \mathrm{CaF}_{2}$ with higher Tm deponent concentrations avoiding clustering. However, a spectral region around $1.45 \mu \mathrm{m}$ associated with a ${ }^{3} \mathrm{H}_{4} \rightarrow{ }^{3} \mathrm{~F}_{4}$ optical transition could be vanished when the $\mathrm{Tm}^{3+}$ dopant concentration is beyond $1.34 \%$ due to [Tm-Tm] clusters [14], and the energy may be absorbed by the ground stated ${ }^{3} \mathrm{H}_{6}$. However, when the concentration of Tm becomes higher, some other possible ways of energy transfer would occur, such as ${ }^{1} \mathrm{G}_{4}+{ }^{3} \mathrm{H}_{4} \rightarrow{ }^{3} \mathrm{~F}_{4}+{ }^{1} \mathrm{D}_{2}$ [17], ${ }^{3} \mathrm{H}_{5} \rightarrow{ }^{3} \mathrm{H}_{6}$ [18], and ${ }^{3} \mathrm{H}_{5}+$ photo $_{800 \mathrm{~nm}} \rightarrow{ }^{1} \mathrm{G}_{4}$. Therefore, we take the advantage of $\mathrm{Y}^{3+}$ as buffer ions reported in $\mathrm{Nd}, \mathrm{Y}: \mathrm{CaF}_{2}[3,8]$ crystals to prepare the Tm, $\mathrm{Y}: \mathrm{CaF}_{2}$ crystals to break the [Tm-Tm] clusters and increase the $\mathrm{Tm}^{3+}$ emission intensity as well as efficiency in higher concentration, and the laser performance and wide emission spectrum have been expected. Importantly, the incorporation of $\mathrm{Y}^{3+}$ ions to the influences of spectroscopic properties in $\mathrm{Tm}^{3+}$ doped $\mathrm{CaF}_{2}$ single crystals had not been investigated systematically.

In this paper, to improve high pump absorption efficiency and high gain per unit length, a series of 3 at. $\%$ Tm and $x$ at.\% $\mathrm{Y}: \mathrm{CaF}_{2}$ crystals have been grown by the vertical Bridgman method, and spectroscopic properties were studied systematically. We have carried out laser experiments and obtained continuous-wave laser output.

\section{Experimental}

The single crystal samples, namely, 3 at.\% Tm, $x$ at.\% Y:CaF ( $x=0,0.5,1,2,3)$ crystals (at. $\%$, atom percent), were grown by the traditional vertical Bridgman method. High purity fluorides crystalline powders $(4 \mathrm{~N}), \mathrm{CaF}_{2}, \mathrm{TmF}_{3}, \mathrm{YF}_{3}$, were used as starting materials, and $1 \mathrm{wt} \% \mathrm{PbF}_{2}$ was selected as an oxygen scavenger avoiding oxidation and volatilization additionally. These materials were completely mixed by molar ratios and filled into an assembled platinum crucible. The growth parameters are as follows: the temperature of the melt around $130^{\circ} \mathrm{C}$, the pulling rate $0.8 \mathrm{~mm} / \mathrm{h}$, the cooling rate $20^{\circ} \mathrm{C} / \mathrm{h}$. The samples (the same thickness of about $2 \mathrm{~mm}$ ) were handled with cutting and double-face optically polishing for spectral measurement.

By recording absorption and emission spectra, we investigated the spectroscopic properties of the crystals. The absorption spectra were measured by using a Jasco V-570 UV/VIS/NIR spectrophotometer. The fluorescence spectra and lifetime were obtained with a FLS980 time-resolved fluorimeter with grating blazed at $1820 \mathrm{~nm}$ and detected using a Hamamatsu InSb. Measuring of fluorescence spectra was performed under pumping at $808 \mathrm{~nm}$ with a CW laser operation. All the measurements were conducted at room temperature.

\section{Results and Discussion}

3.1. Phase Identification and Crystal Structure. 3 at. $\% \operatorname{Tm}, x$ at. $\% \mathrm{Y}: \mathrm{CaF}_{2}$ crystals $(x=0,0.5,1,2,3)$ have been analyzed by powder XRD and behave the purity phase $\mathrm{CaF}_{2}$ without any impure peaks as shown in Figure 1(a). The XRD patterns of the crystals have matched well with the JCPDS standard card of $\mathrm{CaF}_{2}$ ICSD 00-075-0363 indicating that the fluorite cubic structure $(\mathrm{Fm}-3 \mathrm{~m})$ has not been changed by the increasing concentration of yttrium. $\mathrm{Tm}^{3+}$ and $\mathrm{Y}^{3+}$ ions substitute for $\mathrm{Ca}^{2+}$ ions in the $\mathrm{CaF}_{2}$ lattice, and smaller $\mathrm{F}^{-}$ions have taken placed in the interstitial positions of the empty cubes to compensate the charge and maintain electrical neutrality leading to the smaller Bragg's angels and larger lattice parameters 


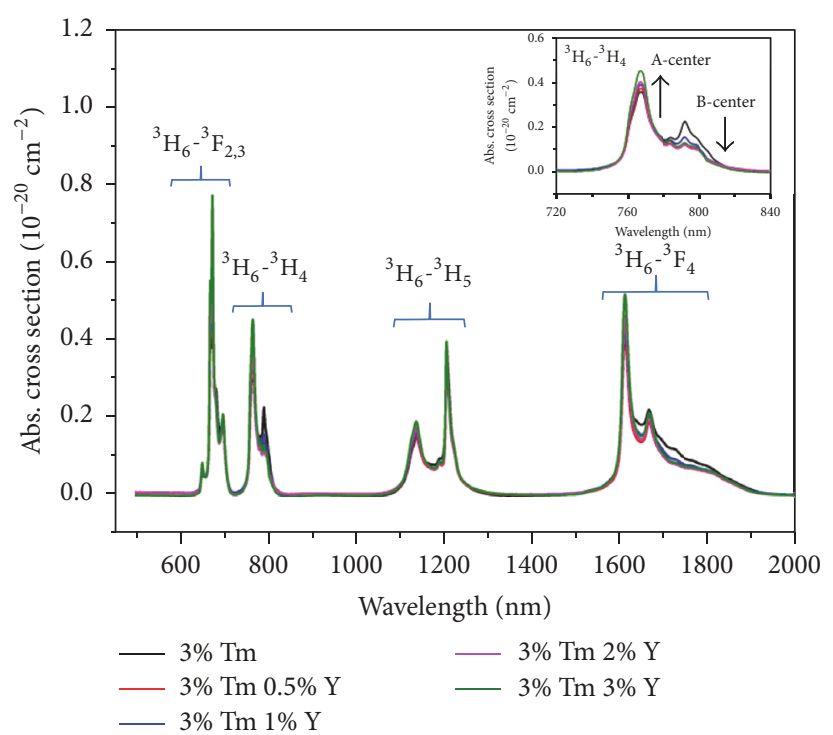

(a)

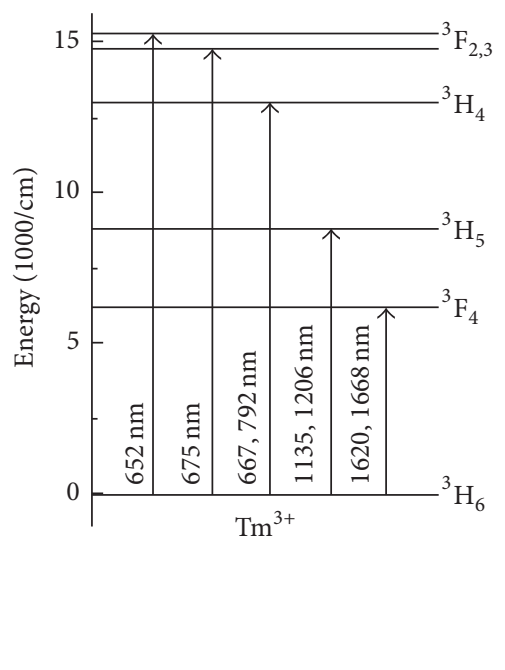

(b)

Figure 2: Absorption spectra (a) and energy level diagrams (b) of 3 at. $\%$ Tm, $x$ at. $\%$ Y:CaF $\mathrm{C}_{2}$ crystals at $300 \mathrm{~K}$.

which could be distinguished clearly on the enlarged view of (111) in Figure 1(a). The lattice parameters of series of 3 at.\% Tm, $x$ at.\% Y:CaF $\mathrm{Ca}_{2}(x=0.5,1,2,3)$ single crystals are $5.46785 \AA, 5.46947 \AA, 5.47535 \AA, 5.4763 \AA$, respectively, much larger than $5.4559 \AA$ of $\mathrm{Tm}: \mathrm{CaF}_{2}$, and increase with the rising codoping $\mathrm{Y}^{3+}$ ion concentration as shown in Figure 1(b). These observations confirm that $\mathrm{Tm}^{3+}$ and $\mathrm{Y}^{3+}$ ions had been effectively doped into the host lattice of $\mathrm{CaF}_{2}$.

3.2. Absorption and Emission Properties. The absorption spectra from $500 \mathrm{~nm}$ to $2000 \mathrm{~nm}$ at room temperature of 3 at.\% $\mathrm{Tm}, x$ at.\% $\mathrm{Y}$ are shown in Figure 2(a). Due to various splitting energy levels of ${ }^{3} \mathrm{H}_{6}$ and ${ }^{3} \mathrm{~F}_{4}$, the absorption bands have been divided into several peaks. Several main absorption bands, ${ }^{3} \mathrm{H}_{6}-{ }^{3} \mathrm{~F}_{2}(652 \mathrm{~nm}),{ }^{3} \mathrm{H}_{6}-{ }^{3} \mathrm{~F}_{3}(675 \mathrm{~nm}),{ }^{3} \mathrm{H}_{6}-$ ${ }^{3} \mathrm{H}_{4}(667 \mathrm{~nm}, 792 \mathrm{~nm}),{ }^{3} \mathrm{H}_{6}-{ }^{3} \mathrm{H}_{5}(1135 \mathrm{~nm}, 1206 \mathrm{~nm}),{ }^{3} \mathrm{H}_{6}{ }^{3}{ }^{3} \mathrm{~F}_{4}$ $(1620 \mathrm{~nm}, 1668 \mathrm{~nm})$, have been marked in the spectra. Clearly, all the absorption cross sections are increased with the $\mathrm{Y}$ ions. Additionally, the absorption ${ }^{3} \mathrm{H}_{6}{ }_{-}{ }^{3} \mathrm{H}_{4}$, which is usually used for diode pumping, inset in the picture has been analyzed in detail at $767 \mathrm{~nm}$ and $792 \mathrm{~nm}$ in the same bands caused by different emission centers, defined as A-center and B-center.

The largest absorption cross section at $767 \mathrm{~nm}$ of 3 at.\% Tm, 3 at.\% Y:CaF 2 improves to $0.45 \times 10^{-20} \mathrm{~cm}^{-2}$, much larger than that reported in [14]. On the other side, the absorption cross section at $792 \mathrm{~nm}$ decreases gradually from $0.22 \times 10^{-20} \mathrm{~cm}^{-2}$ to $0.12 \times 10^{-20} \mathrm{~cm}^{-2}$ with the increasing $\mathrm{Y}$ ions. $\mathrm{Y}$ ions play an important role in modulating spectral performance. The absorption spectra of $\mathrm{Tm}^{3+}$ ions can be significantly altered by codoping with $\mathrm{Y}^{3+}$ ions. The changeable absorption cross sections indicate that the local structure and symmetry of the calcium fluoride crystal have been modified by changing the amount of deponent codoping $\mathrm{Y}^{3+}$ ions. The increasing phenomenon could be attributed to the stronger crystal field caused by interstitial $\mathrm{F}^{-}$ions in the lattice induced by the codoped $\mathrm{Y}^{3+}$ separating the $[\mathrm{Tm}-\mathrm{Tm}]$ clusters, caused by a considerable high doping concentration 3 at.\% much larger than $1.34 \%[11,19]$, to an appropriate distance and forming A-centers instead of B-centers. By doping $\mathrm{Y}^{3+}$ ions, $\mathrm{B}$-center has been broken, forming more A-centers as a result. Anyway, it is clear that codoping $\mathrm{Tm}: \mathrm{CaF}_{2}$ with $\mathrm{Y}^{3+}$ ions slightly broadens the absorption bands ${ }^{3} \mathrm{H}_{6}{ }^{3} \mathrm{H}_{4}$, which should be profitable for $\mathrm{LD}$ pumping. The broad wavelength tunability indicated an efficient ground-state stark splitting with the introduction of $\mathrm{Y}^{3+}$ ions in the as-grown $\mathrm{Tm}, \mathrm{Y}: \mathrm{CaF}_{2}$ crystal.

The fluorescence spectra of 3 at.\% Tm, $x$ at.\% $\mathrm{Y}_{\mathrm{CaF}}$ crystals, corresponding to ${ }^{3} \mathrm{~F}_{4}{ }^{-}{ }^{3} \mathrm{H}_{6}$ emission transition of $\mathrm{Tm}^{3+}$ around $1.8 \mu \mathrm{m}$, excited by $767 \mathrm{~nm}$ are reported in Figure 3. The emission spectra of the five crystals consist of four bands, peaking at $1611 \mathrm{~nm}\left(6207 \mathrm{~cm}^{-1}\right), 1666 \mathrm{~nm}\left(6002 \mathrm{~cm}^{-1}\right)$, $1820 \mathrm{~nm}\left(5494 \mathrm{~cm}^{-1}\right), 1856 \mathrm{~nm}\left(5387 \mathrm{~cm}^{-1}\right)$, respectively. The carves of $\mathrm{Tm}, \mathrm{Y}: \mathrm{CaF}_{2}$ demonstrate several intense separate local maxima compared to the one of the $\mathrm{Tm}: \mathrm{CaF}_{2}$, indicating that the $\mathrm{Y}^{3+}$ ions codoping modulate the emission spectral structure of $\mathrm{Tm}^{3+}$ ions in $\mathrm{CaF}_{2}$ hosts. The emission intensity of 2873 a.u. at $1820 \mathrm{~nm}$ of the 3 at. $\% \mathrm{Tm}, 3$ at. $\% \mathrm{Y}: \mathrm{CaF}_{2}$ crystals is 3.4 times higher than that of the 3 at.\% Tm:CaF ${ }_{2}$ crystal (842 a.u.), whose value is the largest above all the samples. As has been discussed in the absorption cross sections, $\mathrm{Y}^{3+}$ codoping breaks the $\mathrm{Tm}^{3+}$ ion clusters and increases the fluorescence quantum efficiency which could also be proved in Table 1. Additionally, the luminescence intensity of the $1.8 \mu \mathrm{m}$ band is improved by doping $\mathrm{Y}^{3+}$.

Figure 4 shows the logarithm of the emission intensity at $1820 \mathrm{~nm}$ of $\mathrm{Tm}^{3+}$ as a function of the decay time in 3 
TABLE 1: The detailed values of $\sigma_{\mathrm{abs}}, \sigma_{\mathrm{em}}, \tau_{\mathrm{rad}}, \tau_{\mathrm{em}}, \eta$ of 3 at. $\% \mathrm{Tm}, x$ at. $\% \mathrm{Y}: \mathrm{CaF}_{2}$ at $1820 \mathrm{~nm}$.

\begin{tabular}{|c|c|c|c|c|c|}
\hline Crystals & $\sigma_{\mathrm{abs}} / \mathrm{cm}^{2}$ & $\sigma_{\mathrm{em}} / \mathrm{cm}^{2}$ & $\tau_{\mathrm{rad}} / \mathrm{ms}$ & $\tau_{\mathrm{em}} / \mathrm{ms}$ & $\eta / \%$ \\
\hline $\begin{array}{l}3 \text { at. } \% \\
\text { Tm: } \mathrm{CaF}_{2}\end{array}$ & 0.063 & $1.206 * 10^{-20}$ & 10.58 & 6.16 & 58.2 \\
\hline $\begin{array}{l}3 \text { at. } \% \mathrm{Tm}, 0.5 \\
\text { at.\% Y: } \mathrm{CaF}_{2}\end{array}$ & 0.054 & $1.026 * 10^{-20}$ & 11.43 & 7.25 & 63.4 \\
\hline $\begin{array}{l}3 \text { at. } \% \mathrm{Tm}, 1 \\
\text { at. } \% \mathrm{Y}: \mathrm{CaF}_{2}\end{array}$ & 0.057 & $1.090 * 10^{-20}$ & 10.24 & 6.53 & 63.7 \\
\hline $\begin{array}{l}3 \text { at. } \% \mathrm{Tm}, 2 \\
\text { at.\% Y: } \mathrm{CaF}_{2}\end{array}$ & 0.054 & $1.026 * 10^{-20}$ & 10.82 & 7.55 & 69.8 \\
\hline $\begin{array}{l}3 \text { at. } \% \mathrm{Tm}, 3 \\
\text { at. } \% \mathrm{Y}: \mathrm{CaF}_{2}\end{array}$ & 0.056 & $1.088 * 10^{-20}$ & 10.14 & 8.15 & 80.3 \\
\hline
\end{tabular}

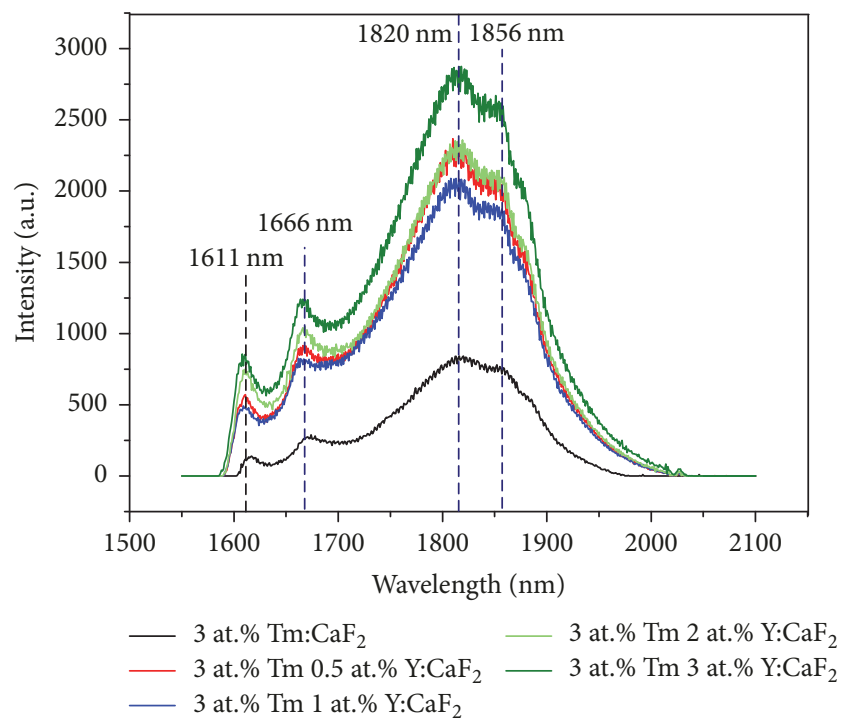

FIgURE 3: Fluorescence spectra for ${ }^{3} \mathrm{~F}_{4}-{ }^{3} \mathrm{H}_{6}$ transition of 3 at.\% Tm, $x$ at. $\% \mathrm{Y} \mathrm{CaF}_{2}$ crystals at $300 \mathrm{~K}$.

at.\% $\mathrm{Tm}, x$ at.\% Y:CaF 2 crystals excited by $767 \mathrm{~nm}$ at room temperature. The straight lines indicated that the decay was consistent with a first-order exponential and the emission lifetimes were labelled as arrows. The emission lifetimes were fitted to be $6.16 \mathrm{~ms}, 7.25 \mathrm{~ms}, 6.53 \mathrm{~ms}, 7.55 \mathrm{~ms}, 8.15 \mathrm{~ms}$ for 3 at. $\% \mathrm{Tm}, x$ at. $\% \mathrm{Y}: \mathrm{CaF}_{2}(x=0,0.5,1,2,3)$, respectively, which is in the order of $5 \mathrm{~ms}$ [11] much shorter than the longer lifetime $15 \mathrm{~ms}$ [20]. Due to the higher concentration of $\mathrm{Tm}^{3+}$, the emission lifetimes caused by the fluorescence of clustered thulium centers and the tetragonal optical centers are responsible for the longer lifetime $15 \mathrm{~ms}[11,20]$. It also could be discussed that the emission centers with higher symmetry could extend the emission lifetime of the energy level ${ }^{3} \mathrm{~F}_{4}$ which could benefit the pump efficiency. The shorter emission lifetime means that in the 3 at.\% Tm, $x$ at.\% Y:CaF 2 crystals, $[\mathrm{Tm}-\mathrm{Tm}]$ clusters take a dominant station affecting the lifetime of ${ }^{3} \mathrm{~F}_{4}$ compared to these tetragonal optical centers. The emission lifetimes of Tm, $\mathrm{Y}: \mathrm{CaF}_{2}$ crystals were longer than that of the $\mathrm{Tm}: \mathrm{CaF}_{2}$ crystal, indicating clearly that

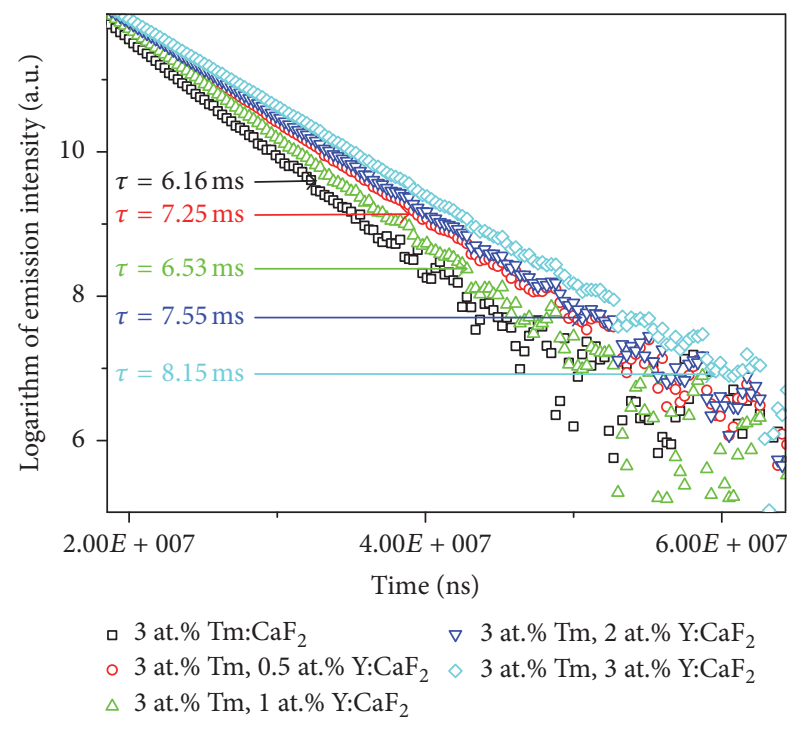

Figure 4: Fluorescence lifetimes of energy level ${ }^{3} \mathrm{~F}_{4}$ of 3 at.\% Tm, $x$ at. $\% \mathrm{Y}: \mathrm{CaF}_{2}$ crystals.

codoping $\mathrm{Y}^{3+}$ ions as buffer ions increase the fluorescence lifetime of Tm ions.

3.3. Calculations for Spectral Parameters. In this session, some spectral parameters including the emission cross section $\sigma_{\mathrm{em}}$, the radiation lifetimes $\tau_{\mathrm{rad}}$, the quantum efficiency $\eta$, the quality factor $\sigma_{\mathrm{em}} * \tau_{\mathrm{em}}$, the effective linewidth $\Delta \lambda$ have been calculated to measure the quality of these crystals. The emission cross section $\sigma_{\mathrm{em}}$ and the radiation lifetimes $\tau_{\mathrm{rad}}$ have been calculated by the reciprocity method and the Fuchtbauer-Ladenburg (FL) equation, respectively, and the absorption cross sections $\sigma_{\mathrm{abs}}$ could be obtained from the absorption spectra in Figure 2(a).

$$
\sigma_{\mathrm{em}}(\lambda)=\sigma_{\mathrm{abs}}(\lambda) \frac{Z_{l}}{Z_{u}} \exp \left[\frac{h c}{k_{B} T}\left(\frac{1}{\lambda_{\mathrm{ZL}}}-\frac{1}{\lambda}\right)\right],
$$

where $\lambda_{\mathrm{ZL}}$ will be referred to as the "zero line" wavelength $\left(\lambda_{\mathrm{ZL}}=1666 \mathrm{~nm}\right.$ wavelength associated with the transition between the lowest stark components of each multiplet ${ }^{3} \mathrm{H}_{6}$ and $\left.{ }^{3} \mathrm{~F}_{4}\right)$ and $Z_{l} / Z_{u}$ represents the ratio of the partition functions of the lower and upper states and the value is 1.512 [14].

$$
\sigma_{\mathrm{em}}=\frac{\lambda_{\text {peak }}^{4}}{8 \pi n^{2} \Delta \lambda \cdot \tau_{\mathrm{rad}}},
$$

where $\lambda_{\text {peak }}$ is the wavelength of the maximum emission intensity (here is $1820 \mathrm{~nm}$ ) and $n$ stands for the refractive index (the refractive index of calcium fluoride is 1.442 at $1820 \mathrm{~nm}$ ). We can take advantage of (2) for the value of $\tau_{\text {rad. }}$. In theory, the product of $\sigma_{\mathrm{em}}$ and $\tau_{\mathrm{rad}}$ is inversely proportional to $\Delta \lambda$. It indicates that the result of the experiment is nearly 


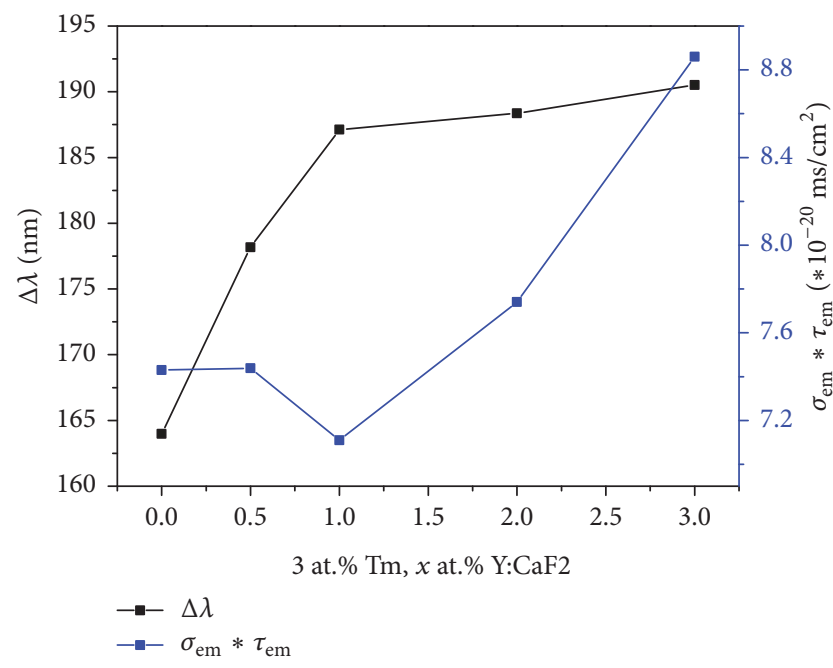

Figure 5: $\tau_{\text {rad }} * \sigma_{\text {em }}$ and $\Delta \lambda$ obtained from 3 at. $\%$ Tm, $x$ at. $\%$ Y:CaF $\mathrm{Ca}_{2}$ crystals.

in agreement with that of the theory. Equation (2) can also be expressed as

$$
\sigma_{\mathrm{em}} \cdot \tau_{\mathrm{em}}=\frac{\lambda_{\mathrm{peak}}^{4}}{8 \pi c n^{2}} \cdot \frac{1}{\Delta \lambda} \cdot \frac{\tau_{\mathrm{em}}}{\tau_{\mathrm{rad}}}=\frac{\lambda_{\mathrm{peak}}^{4}}{8 \pi c n^{2}} \cdot \frac{1}{\Delta \lambda} \cdot \eta
$$

where $\lambda_{\text {peak }}^{4} / 8 \pi c n^{2}$ can be regarded as a constant and $\eta$ is the quantum efficiency. The calculated results have been shown in Table 1 and Figure 5.

The emission cross section $\sigma_{\mathrm{em}}$ varies from $1.026 *$ $10^{-20} / \mathrm{cm}^{2}$ to $1.088 * 10^{-20} / \mathrm{cm}^{2}$. The quantum efficiency of emission at $1820 \mathrm{~nm}$ is $58.2 \%, 63.4 \%, 63.7 \%, 69.8 \%, 80.3 \%$ for 3 at. $\% \mathrm{Tm}, x$ at. $\% \mathrm{Y}(x=0,0.5,1,2,3)$, respectively. As discussed above, cooping Y ions as buffer ions actually benefit the quantum efficiency increasing the quantum efficiency effectively, indicating that the efficiency of the fluoresce is very sensitive to the cationic coordination [21], and the highest quantum efficiency has been increased to $80.3 \%$.

We can see the difference of $\Delta \lambda$ (where $\Delta \lambda$ is the effective linewidth which can be obtained by measurement) from Figure 4 . The change trend of the effective linewidth at $1820 \mathrm{~nm}$ is depicted in Figure 5, which is almost increasing with codoping $\mathrm{Y}^{3+}$ ion concentration. $\Delta \lambda$ at $1820 \mathrm{~nm}$ is $163.97 \mathrm{~nm}, 178.16 \mathrm{~nm}, 187.12 \mathrm{~nm}, 188.37 \mathrm{~nm}, 190.52 \mathrm{~nm}$ for 3 at. $\% \mathrm{Tm}, x$ at. $\% \mathrm{Y}: \mathrm{CaF}_{2}(x=0,0.5,1,2,3)$, respectively, behaving the superiority for LD pumping. Compared with single-doped one, the effective linewidth of the codoping crystals increased rapidly, and the trend turns out to be saturated when the concentration of $\mathrm{Y}^{3+}$ grows higher. It indicates that the effect of $\mathrm{Y}^{3+}$ concentration on the effective linewidth causes saturation which is in favor of femtosecond laser output.

3.4. Laser Performance. Taking both emission intensity and lifetime into consideration, two samples, 3 at.\% Tm:CaF 2 and 3 at. $\% \mathrm{Tm}, 3$ at.\% Y: $\mathrm{CaF}_{2}$, were applied in laser experiments as laser-pumped-amplifier mediums. The size of the crystal is
$4 \mathrm{~mm} \times 4 \mathrm{~mm} \times 6 \mathrm{~mm}$ and the end faces were optically polished flat and parallel without being coated. The continuouswave $(\mathrm{CW})$ experiment with a fiber-coupled AlGaAs diode laser as the pump source emitting at $790 \mathrm{~nm}$ was carried out at room temperature, and the setup for testing was shown in Figure 6.

In this experiment, the output mirror transmission is $2 \%$, and the folded cavity consisted of three mirrors: M1, $\mathrm{M} 2$, and M3, having the same radium of curvature of $10 \mathrm{~cm}$. The pump light was focused into the crystal through a $1: 1$ optical imaging module. The pump source was provided by a laser diode around $790 \mathrm{~nm}$. The laser output powers of two samples were depicted in Figure 7, we obtained two different laser curves. To the sample, 3 at.\% Tm, 3 at.\% Y:CaF ${ }_{2}$ crystal, its laser slope efficiency and maximum output power of the crystal are $25.3 \%$ and $583 \mathrm{~mW}$ with the $2 \%$ transmission output coupler, while a lower slope efficiency of $15.9 \%$ and maximum output power $159 \mathrm{~mW}$ were obtained with 3 at.\% $\mathrm{Tm}: \mathrm{CaF}_{2}$ crystal. The maximum pump power was limited by the absorption capacity of the 3 at.\% Tm: $\mathrm{CaF}_{2}$ crystal. We found its excited state absorption tended to be saturated when the absorbed pump power was over $1.6 \mathrm{~W}$. To avoid damage, the absorbed pump power of 3 at. $\% \mathrm{Tm}: \mathrm{CaF}_{2}$ was set below $1.6 \mathrm{~W}$ corresponding to the incident pump power of $3 \mathrm{~W}$, and the absorbed pump power of 3 at. $\% \mathrm{Tm}, 3$ at. $\% \mathrm{Y}: \mathrm{CaF}_{2}$ crystal was set below $2.5 \mathrm{~W}$ corresponding to the incident pump power of $4.5 \mathrm{~W}$.

\section{Conclusions}

The codoping $\mathrm{Y}^{3+}$ ions $\mathrm{Tm}: \mathrm{CaF}_{2}$ crystals were successfully grown by vertical Bridgman method, and the properties of the series crystals were analyzed systematically. Absorption of ${ }^{3} \mathrm{H}_{6}{ }^{3} \mathrm{H}_{4}$ is caused by A-center at $767 \mathrm{~nm}$ and B-center at $792 \mathrm{~nm}$, and the absorption cross section of A-center is increased while the absorption cross section of B-center is decrease by codoping $\mathrm{Y}^{3+}$. Emission intensity and effective linewidth of emission at $1820 \mathrm{~nm}$ are greatly improved when the concentration increased to 3 at. $\%$. The quantum efficiency is enhanced to $80.3 \%$ by codoping $\mathrm{Y}^{3+}$ ions compared to the undoped crystals. It demonstrates codoping $\mathrm{Y}^{3+}$ ions have a positive effect on spectroscopic properties. In laser experiment, we finally obtained a maximum laser output power of $583 \mathrm{~mW}$ and slope efficiency of $25.3 \%$ in codoped sample.

\section{Conflicts of Interest}

The authors declare that they have no conflicts of interest.

\section{Acknowledgments}

This work was financially supported by the National Natural Science Foundation of China (Grants nos. 61422511, 61635012, and 61475089) and The National Key Research and Development Program of China (Grant no. 2016YFB0402101). 


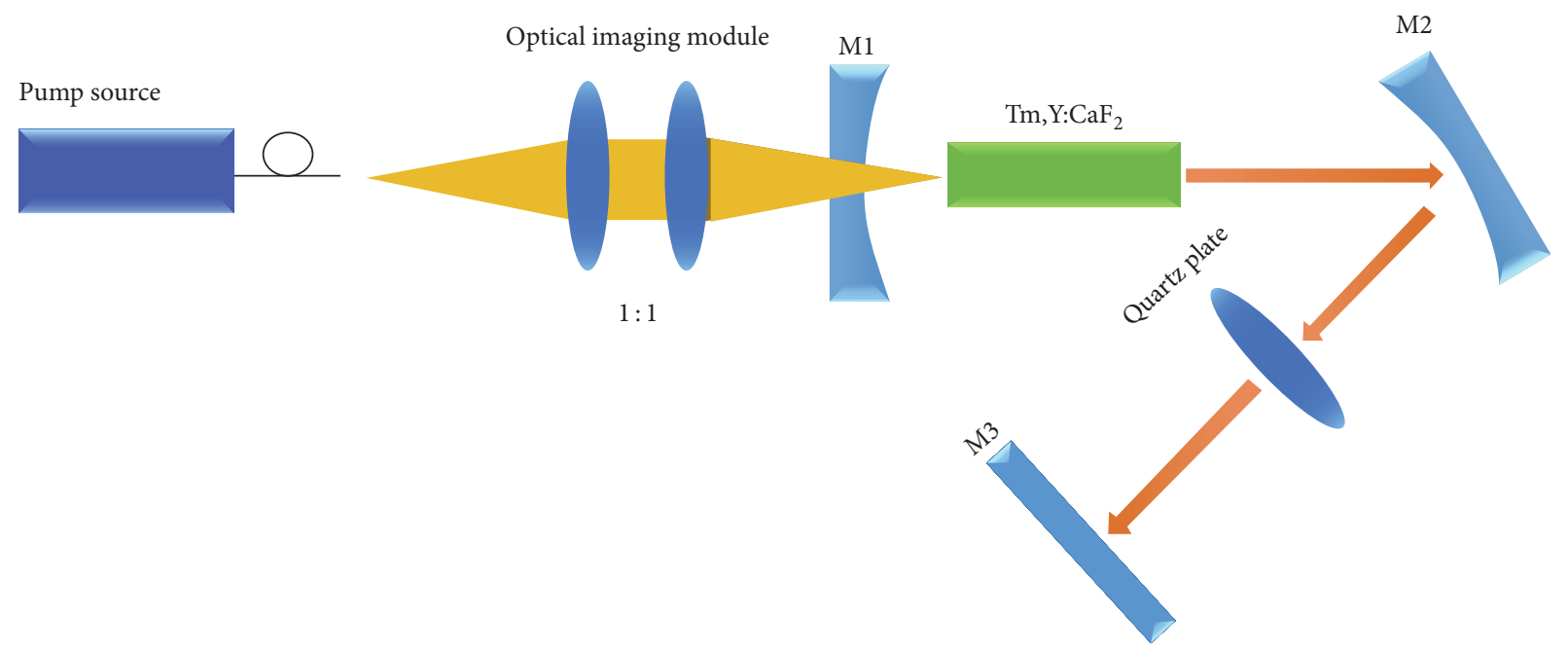

FIGURE 6: Schematic of the experimental setup for $1.8 \mu \mathrm{m}$ laser operation.

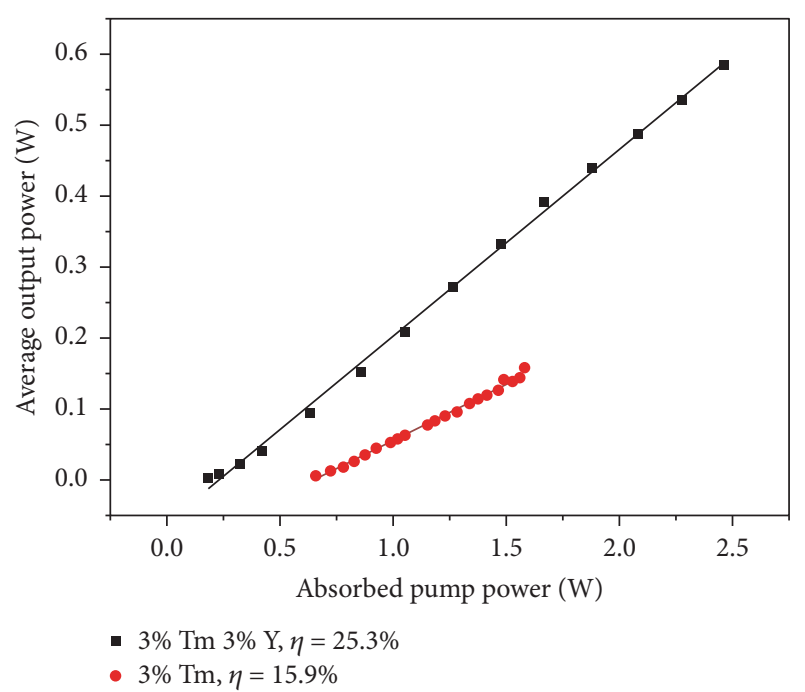

Figure 7: Laser output power versus absorbed pump power curve for 3 at. $\%$ Tm: $\mathrm{CaF}_{2}$ and 3 at. $\%$ Tm, 3 at. $\%$ Y: $\mathrm{CaF}_{2}$ crystals.

\section{References}

[1] C. R. A. Catlow, A. V. Chadwick, G. N. Greaves, and L. M. Moroney, "Direct observations of the dopant environment in fluorites using EXAFS," Nature, vol. 312, no. 5995, pp. 601-604, 1984.

[2] S. A. Payne, J. A. Caird, L. L. Chase, L. K. Smith, N. D. Nielsen, and W. F. Krupke, "Spectroscopy and gain measurements of $\mathrm{Nd}^{3+}$ in $\mathrm{SrF}_{2}$ and other fluorite-structure hosts," Journal of the Optical Society of America B: Optical Physics, vol. 8, no. 4, pp. 726-740, 1991.

[3] T. P. J. Han, G. D. Jones, and R. W. G. Syme, "Site-selective spectroscopy of $\mathrm{Nd}^{3+}$ centers in $\mathrm{CaF}_{2}: \mathrm{Nd}^{3+}$ and $\mathrm{SrF}_{2}: \mathrm{Nd}^{3+}$," Physical Review B: Condensed Matter and Materials Physics, vol. 47, no. 22, pp. 14706-14723, 1993.

[4] N. E. Kask and L. S. Kornienko, "EPR of $\mathrm{Nd}^{3+}$ ions in fluorite," Journal of Experimental and Theoretical Physics, vol. 26, pp. 331335, 1968.
[5] A. A. Kaminskii, V. V. Osiko, A. M. Prochoro, and Y. K. Voronko, "Spectral investigation of stimulated radiation of $\mathrm{Nd}^{3+}$ in $\mathrm{CaF}_{2}$ $\mathrm{YF}_{3}$," Physics Letters, vol. 22, pp. 419-421, 1966.

[6] K. S. Bagdasarov, Y. K. Voronko, A. A. Kaminskii, L. V. Krotova, and V. V. Osiko, "Modification of the optical properties of $\mathrm{CaF}_{2}-$ $\mathrm{TR}^{3+}$ crystals by yttrium impurities," Physica Status Solidi, vol. 12, no. 2, pp. 905-912, 1965.

[7] T. T. Basiev, Y. K. Voronko, A. Y. Karasik, V. V. Osiko, and I. A. Shcherbakov, "Spectral migration of electronic excitation along $\mathrm{Nd}^{3+}$ ions in $\mathrm{CaF}_{2}-\mathrm{YF}_{3}$ crystal on selective laser excitation," Journal of Experimental and Theoretical Physics, vol. 75, pp. 66$74,1978$.

[8] D. Jiang, Y. Zhan, Q. Zhang et al., "Nd, $\mathrm{Y}: \mathrm{CaF}_{2}$ laser crystals: novel spectral properties and laser performance from a controlled local structure," CrystEngComm, vol. 17, pp. 7398-7405, 2015.

[9] H. Wang, J. Zhu, Z. Gao et al., "Femtosecond mode-locked Nd,La:CaF ${ }_{2}$ disordered crystal laser," Optical Materials Express, vol. 6, no. 7, pp. 2184-2189, 2016.

[10] J. Zhang, J. Zhu, J. Wang, Z. Wei, L. Su, and J. Xu, "CW laser performance of $\mathrm{Nd}-\mathrm{La} \cdot \mathrm{CaF}_{2}$ and $\mathrm{Nd}-\mathrm{Sc} \cdot \mathrm{CaF}_{2}$ disordered crystals pumped by a laser diode," Acta Photonica Sinica, vol. 45, pp. 114001-1-114001-5, 2016.

[11] M. E. Doroshenko, O. K. Alimov, A. G. Papashvili et al., "Spectroscopic and laser properties of $\mathrm{Tm}^{3+}$ optical centers in $\mathrm{CaF}_{2}$ crystal under $795 \mathrm{~nm}$ diode laser excitation," Laser Physics Letters, vol. 12, no. 12, Article ID 125701, 2015.

[12] P. J. D. Lindan and M. J. Gillan, "A molecular dynamics study of the thermal conductivity of $\mathrm{CaF}_{2}$ and $\mathrm{UO}_{2}$," Journal of Physics: Condensed Matter, vol. 3, no. 22, pp. 3929-3939, 1991.

[13] V. Petit, L. Doualan, P. Camy, V. Ménard, and R. Moncorgé, “CW and tunable laser operation of $\mathrm{Yb}^{3+}$ doped $\mathrm{CaF}_{2}$," Applied Physics B, vol. 78, p. 681, 2004.

[14] P. Camy, J. L. Doualan, S. Renard, A. Braud, V. Ménard, and R. Moncorgé, " $\mathrm{Tm}^{3+}: \mathrm{CaF}_{2}$ for $1.9 \mu \mathrm{m}$ laser operation," Optics Communications, vol. 236, no. 4-6, pp. 395-402, 2004.

[15] N. M. Strickland and G. D. Jones, "Site-selective spectroscopy of $\mathrm{Tm}^{3+}$ centers in $\mathrm{CaF}_{2}: \mathrm{Tm}^{3+}$," Physical Review B: Condensed Matter and Materials Physics, vol. 56, no. 17, pp. 10916-10929, 1997. 
[16] J. Ganem and S. R. Bowman, "Use of thulium-sensitized rare earth-doped low phonon energy crystalline hosts for IR sources," Nanoscale Research Letters, vol. 8, p. 455, 2013.

[17] H. Zhang, Y. Li, Y. Lin, Y. Huang, and X. Duan, "Composition tuning the upconversion emission in $\mathrm{NaYF}_{4}: \mathrm{Yb} / \mathrm{Tm}$ hexaplate nanocrystals," Nanoscale, vol. 3, no. 3, pp. 963-966, 2011.

[18] X. Bai, D. Li, Q. Liu, B. Dong, S. Xu, and H. Song, "Concentration-controlled emission in $\mathrm{LaF}_{3}: \mathrm{Yb}^{3+} / \mathrm{Tm}^{3+}$ nanocrystals: switching from UV to NIR regions," Journal of Materials Chemistry, vol. 22, no. 47, pp. 24698-24704, 2012.

[19] P. J. Bendall, C. R. A. Catlow, J. Corish, and P. W. M. Jacobs, "Defect aggregation in anion-excess fluorites II. Clusters containing more than two impurity atoms," Journal of Solid State Chemistry, vol. 51, no. 2, pp. 159-169, 1984.

[20] M. E. Doroshenko, A. G. Papashvili, O. K. Alimov et al., "Specific spectroscopic and laser properties of $\mathrm{Tm}^{3+}$ ions in hotformed $\mathrm{CaF}_{2}$ laser ceramics," Laser Physics Letters, vol. 13, no. 1, Article ID 015701, 2016.

[21] G. Lakshminarayana, R. Yang, M. Mao, J. Qiu, and I. V. Kityk, "Photoluminescence of $\mathrm{Sm}^{3+}, \mathrm{Dy}^{3+}$, and $\mathrm{Tm}^{3+}$-doped transparent glass ceramics containing $\mathrm{CaF}_{2}$ nanocrystals," Journal of Non-Crystalline Solids, vol. 355, no. 52-54, pp. 2668-2673, 2009. 

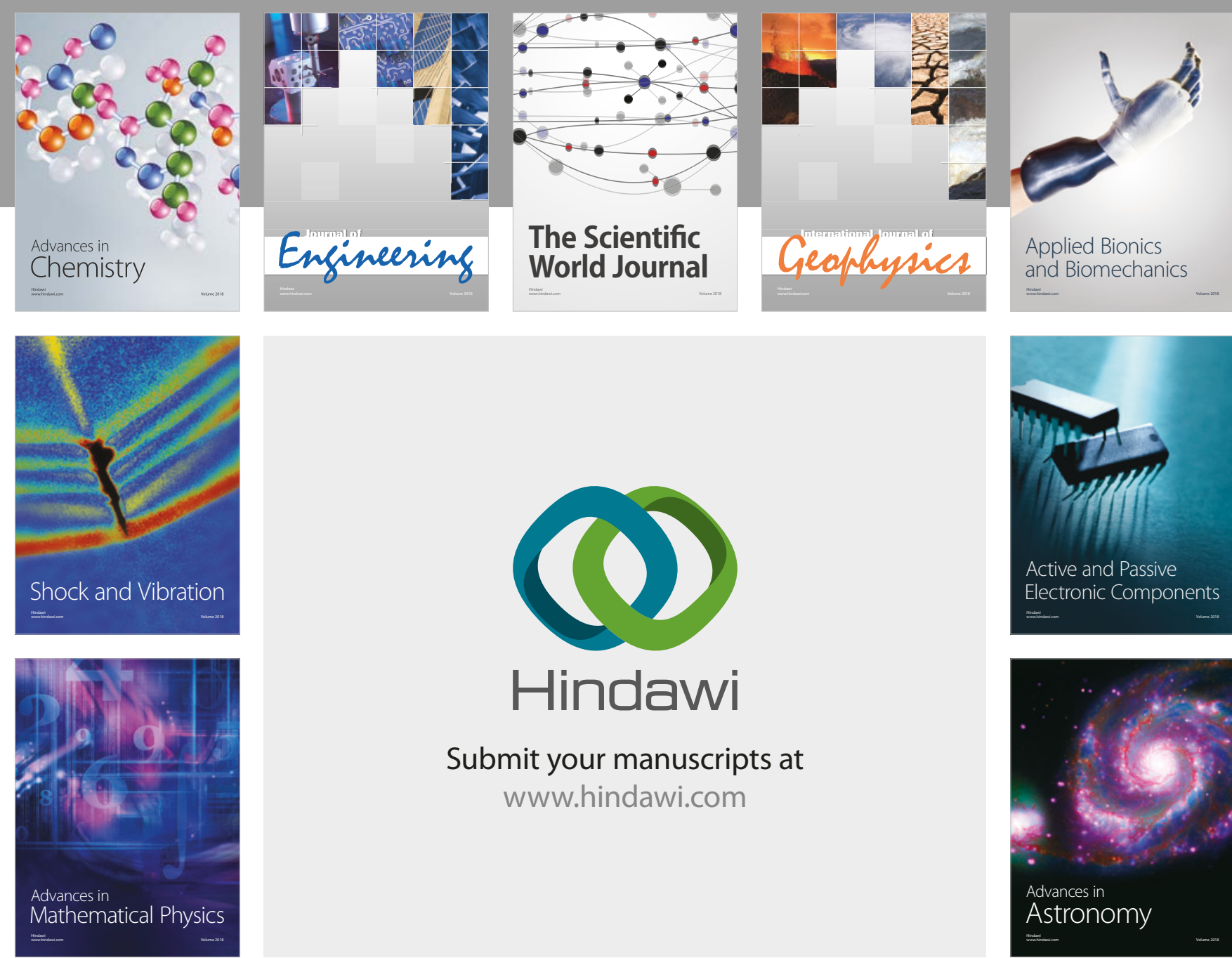

Submit your manuscripts at

www.hindawi.com

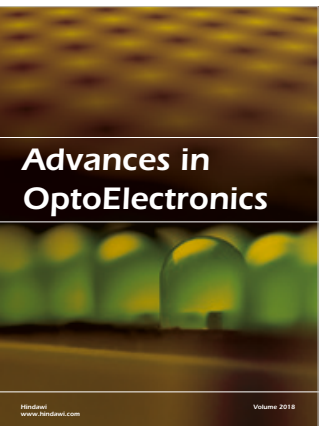

\section{Rotcting Machinery}
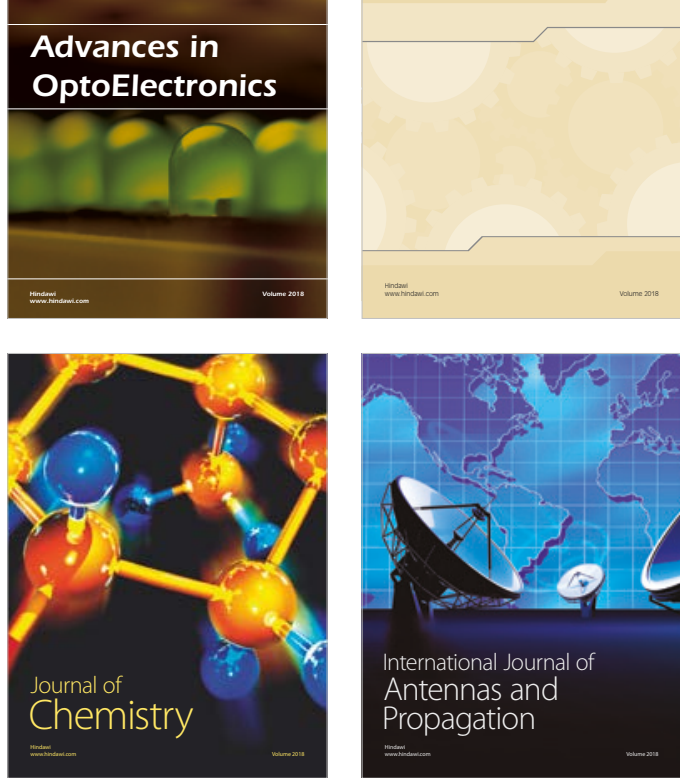

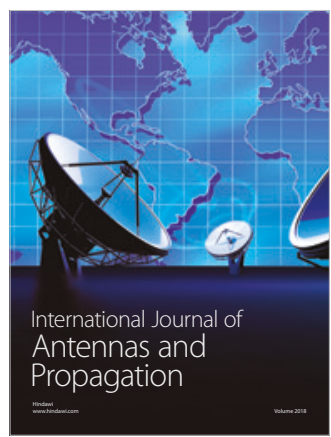

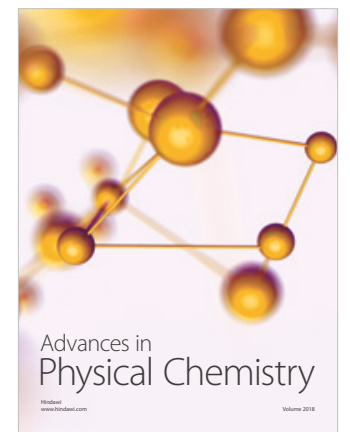

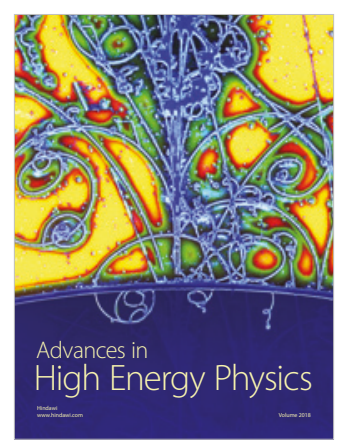

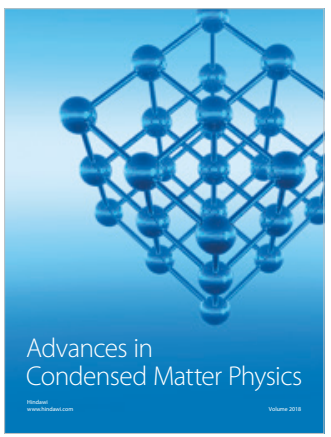

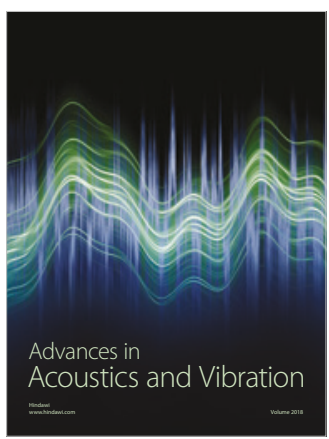

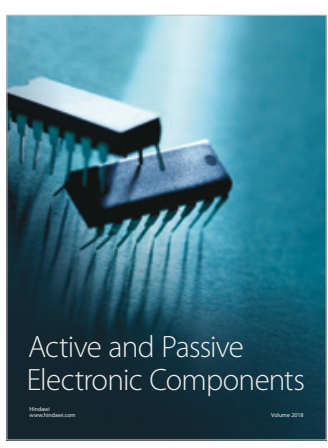
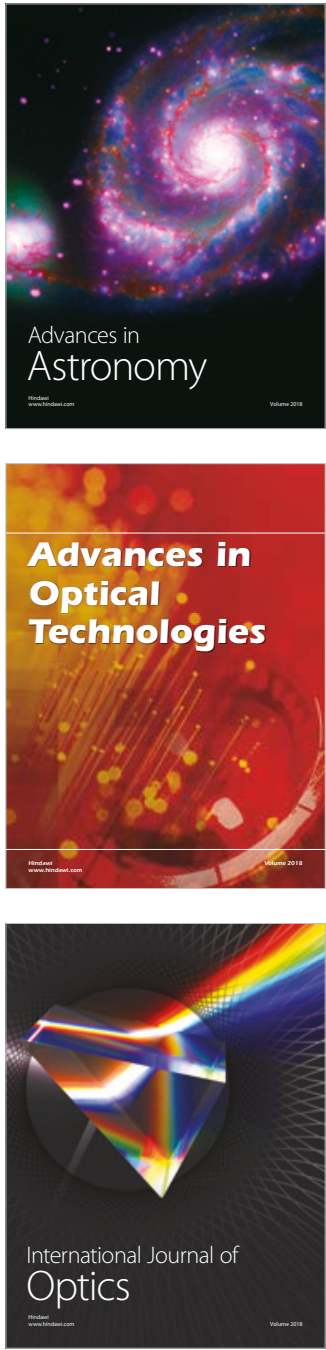